\title{
Optimization of the recipe of toothpaste by carrageenan addition
}

\author{
Olena Podobii, Maryna Ladonko
}

National University of Food Technologies, Kyiv, Ukraine

\section{Keywords:}

Toothpaste

Recipe

Carrageenan

Rheology

Organoleptic

\section{Article history:}

Received 29.05.2017

Received in revised form 17.06.2017

Accepted 05.09.2017

\section{Corresponding author:}

Maryna Ladonko

E-mail:

marinka1805@gmail.com

DOI: $10.24263 / 2310-$

1008-2017-5-1-9

\section{Abstract}

Introduction. The physicochemical properties of toothpaste with the addition of carrageenan to optimize the structure of the toothpaste have been investigated.

Materials and methods. Three samples of toothpaste with containing carrageenan from $1 \%$ to weight to $3 \%$ to weight and a sample with $1 \%$ containing to the weight or sodium carboxymethyl cellulose (NaCMC) were prepared. The rheological parameters of the samples are determined using a rotary viscometer. Organoleptic assessment of the quality of toothpaste is carried out by using a descriptorprofile method.

Results and discussion. The list of organoleptic parameters is proposed. There are consistency, color, smell, taste. 5-point scale of assessments is also proposed. Profiling of quality metrics on this scale has been done. The best consistency for a toothpaste has a sample with $2 \%$ content of carrageenan to weight. The highest color rating have the samples of toothpaste with $1 \%$ and $2 \%$ content of carrageenan to weight. The smell and taste are satisfactory for all toothpaste samples. The best overall assessment of organoleptic quality parameters was obtained samples of toothpaste that contain $1 \%$ to weight $\mathrm{NaCMC}$ and $2 \%$ and $3 \%$ to weight of carrageenan. According to organoleptic indications, the most expedient is adding of carrageenan in an amount of $2 \%$ to weight. According to the rheological parameters, the indexes of the greatest viscosity of the system with practically no damaged structure $\left(\eta_{\mathrm{m}}=76,16 \mathrm{~Pa} \cdot \mathrm{s}\right)$ and the least viscosity of the system with a practically destroyed structure $\left(\eta_{0}=86,37 \mathrm{~Pa} \bullet \mathrm{s}\right)$ are optimal. Adding of carrageenan form a gel-like consistency of the toothpaste. Regarding the calculated rheological parameters of this paste sample, which characterize the strength of structural bonds $\left(\mathrm{Pk}_{1} / \mathrm{Pk}_{2}=1,68\right)$ and the range of stresses $\left(\mathrm{P}_{\mathrm{m}} / \mathrm{Pk}_{1}=8,87\right)$, which structure destruction occurs, are also satisfactory.

Conclusion. The resulting toothpaste with $2 \%$ content of carrageenan has a gel structure. The introduction of the additive optimizes the properties of the components of the toothpaste and promotes a rational impact on the physiological features of the oral cavity. 


\section{Introduction}

The toothpaste is a cosmetic product for the care of the teeth and oral cavity, which is a suspension of abrasive-polishing substances in a water-glycerine solution with the addition of aromatic, biologically active, odor and surface-active, special medical and preventive components.

The ratio of toothpaste components determines the properties, purpose, mechanism of action and efficiency of the toothpaste.

Paste-like consistency of toothpaste allows entering various useful additives that have therapeutic and prophylactic action. Toothpastes are convenient and hygienic using. Currently, toothpastes are the most commonly used oral care products. Hygienic and therapeutic and prophylactic toothpastes are a massive oral care product, therefore the consumer's qualities of this product - color, taste, form $\left[{ }^{1}\right]$ - play an important role.

The development of new technologies for competitive cosmetic products with high consumer, biological value and long shelf life is a perspective direction for the development of the cosmetic industry. Properties of toothpastes are largely determined by the characteristics of thickeners, such as viscosity and plasticity. The thickeners make up from $0,5 \%$ to $2,0 \%$ to weight of paste. That is why the paste is easily extruded from the tube, doesn't spread on the brush, and is easily distributed in the oral cavity. These substances also contribute to reducing the abrasiveness of the toothpaste while retaining cleansing and polishing properties. Hydrocolloids are used as gelling agents in most toothpastes. Viscosity, ductility and thixotropy to gel pastes are provided by natural and synthetic hydrocolloids. Natural hydrocolloids that are extracted from seaweed include sodium alginate and sodium carrageenate. Occasionally use vegetable gum and pectin derived from fruits and juices.

Arne Graf-Andersen, Garris Bicksler, Kenneth Nassen is considered that carrageenan is a perspective in producing toothpastes.

Adding a nutritional supplement E407 - carrageenan, obtained by extraction of red algae improve the physico-chemical properties of toothpastes to their composition $\left[{ }^{2}\right]$. Carrageenan is a very good stabilizer and gellant, it keeps the structure of the substance, even at room temperature and low heating, prevents the formation of lumps, its drying and hardening $\left[{ }^{3}\right]$. It is perfectly compatible with any natural and synthetic materials, therefore has found wide applying in cosmetology $\left[{ }^{4,5}\right]$.

\section{Materials and methods}

Based on the compiled and calculated recipes, 4 toothpastes with different content of carrageenan were prepared, samples were prepared in the laboratory of the department of chemical technologies of food supplements and cosmetic products:

- $\quad$ sample $1-1 \%$ content of sodium carboxymethyl cellulose.

- $\quad$ sample $2-1 \%$ carrageenan content;

- $\quad$ sample $3-2 \%$ of carrageenan content;

- sample $4-3 \%$ content of carrageenan.

According to the recipe of Table 1, four samples of toothpaste with different content of carrageenan were prepared: 
Toothpaste recipes

\begin{tabular}{|l|c|c|c|c|}
\hline \multirow{2}{*}{ Composition } & \multicolumn{4}{c|}{ Weight, g } \\
\cline { 2 - 5 } & Sample №1 & Sample №2 & Sample №3 & Sample №4 \\
\hline Calcium carbonate & 20,00 & 20,00 & 19,20 & 18,80 \\
\hline Glycerin & 5,00 & 5,00 & 4,80 & 4,70 \\
\hline Sorbitol & 5,00 & 5,00 & 4,80 & 4,70 \\
\hline $\begin{array}{l}\text { Sodium } \\
\text { carboxymethylcellulose }\end{array}$ & 0,50 & 0,00 & 0,00 & 0,00 \\
\hline Carraggenan & 0,00 & 0,50 & 1,00 & 1,50 \\
\hline Sodium lauryl sulfate & 0,90 & 0,90 & 0,86 & 0,85 \\
\hline Calcium glycerophosphate & 0,75 & 0,75 & 0,72 & 0,71 \\
\hline $\begin{array}{l}\text { Sodium } \\
\text { monofluorophosphate }\end{array}$ & 0,50 & 0,50 & 0,48 & 0,47 \\
\hline Dioxide of titanium & 0,50 & 0,50 & 0,48 & 0,47 \\
\hline Saccharin & 0,05 & 0,05 & 0,05 & 0,05 \\
\hline Aroma & 1,00 & 1,00 & 1,00 & 1,00 \\
\hline Water & 15,80 & 15,80 & 16,60 & 16,80 \\
\hline
\end{tabular}

Sodium lauryl sulfate was dissolved in a portion of purified water (five times the amount of sodium lauryl sulfate) at a temperature of $60-70{ }^{\circ} \mathrm{C}$. In the porcelain mortar, the recipe amounts of calcium carbonate, calcium of glycerophosphate, sodium monofluorophosphate, sorbitol, titanium dioxide and saccharin were thoroughly rubbed. To the resulting mixture was added a solution of sodium lauryl sulfate, glycerol and carrageenan. After thorough mixing, the flavor was added.

The manufactured toothpaste is packaged and labeled according to the sample number.

The rheological properties of the structured systems were studied, the potentiometer readings for each of the studied systems were studied at different (twelve) deformation rates and the steady stresses of the displacement $\mathrm{P}=$ const.

The study of structural and mechanical properties of the samples were performed on viscometer $\left[{ }^{6}\right]$. Viscosity measurements were carried out using the device, which operates on a constant shear rate.

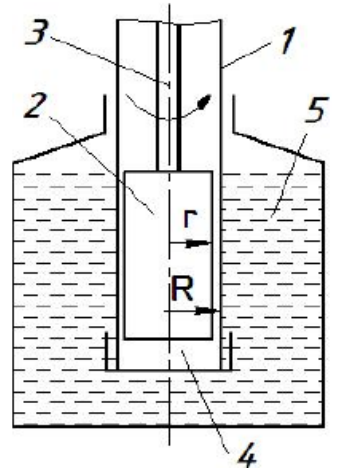

Figure 1. Chart of device

1. Prepare a sample of 50 gram of the set system, mix her and maintain 20-30 minutes.

2. In the immobile external cylinder of device 1 (Figure 1) inundate $30-40 \mathrm{~cm}^{3}$ of the investigated system.

3. Put an internal cylinder 2 on an axis 3 that is connected with an electric engine.

4. An external cylinder 1 with the structured system is put on the fixed internal cylinder 2 and lift to support.

5. Fix position of external cylinder by means of nut. The investigated system is evenly distributed in a gap 4between coaxial cylinders (external 1 and internal 2). If necessary the system is maintained in a thermostat 5 at a certain temperature (Figure 1) 
6. On condition of permanent tension of change $\mathrm{P}=$ const to the internal cylinder deformations (12 or 24) give certain permanent speed, here an external cylinder staysstill.

7. Register velocity of circulation of movable cylinder 2 by means of potentiometer. Velocity of circulation of cylinder is proportional to speed of deformation of the investigated system.

8. Tensions of change of $\mathrm{P}$ expect, that arises up in the system, after equalization:

$$
\mathrm{P}=\mathrm{Z} \cdot \alpha
$$

$\mathrm{Z}$ - became internal cylinder (driven to the passport of device, for example, for the cylinder of $\mathrm{S} 2-\mathrm{Z}=5,39 \mathrm{~Pa}) ; \alpha-$ it is a value of scale on an indicatory device (potentiometer).

9. The values of gradients of deformation $\dot{\varepsilon}$ for every velocity of circulation (12 values) take from passport data.

10. After the values of tension of change of $P$ and gradient of deformation $\varepsilon$ expect dynamic viscidity $\eta$ :

$$
\eta=P / \dot{\varepsilon}
$$

$\eta$-dynamic viscidity, $\mathrm{Pa} \cdot \mathrm{s} ; \mathrm{P}$ - is tension of change, $\mathrm{Pa} ; \boldsymbol{\varepsilon}$ - it is speed of change.

11. The experimental data build complete rheological curves of viscosity $\eta=f(P)$ and fluidity $\dot{\boldsymbol{\varepsilon}}=f(P)$.

The rheological parameters of the toothpaste, which characterize the strength of structural bonds and the range of stresses in which the structure is destroyed are calculated $\left[{ }^{7}\right]$.

An organoleptic assessment of the quality of toothpastes is carried out using the descriptor-profile method $\left[^{8}\right]$.

Appearance, color, smell and taste were determined organoleptically by applying a small amount of paste on a smooth glass plate. Light grains were determined by the absence of grains, as well as the color, smell and taste of the paste.

Not all consumer goods in standards have developed a description of quality indicators and their characteristics.

We were offered a list of organoleptic indicators:

1. Appearance.

2. Color.

3. Smell.

4. Taste.

A 5-point scale was created and profiles of quality indicators were performed on scale. This made it possible to systematically approach the quality assessment and clearly assess the quality of indicators and determine the level of quality. Also, identify indicators with significant deviations.

\section{Results and discussion}

We carried out an organoleptic assessment of the quality of toothpastes. Depending on the composition, the toothpastes must comply with the requirements and norms approved by the normative documentation. Form, color, smell and taste were determined by applying a small amount of paste to a smooth glass plate. The light grains recorded the absence of grains, as well as the color, smell and taste of the paste. The results are presented in Table 2. 
Results of organoleptic quality assessment

\begin{tabular}{|l|c|c|c|c|}
\hline \multirow{2}{*}{ Quality } & \multicolumn{4}{|c|}{ Examples } \\
\cline { 2 - 5 } Appearance & $\begin{array}{c}\text { Consistency } \\
\text { paste, with } \\
\text { small grains }\end{array}$ & $\begin{array}{c}\text { Consistency of } \\
\text { liquid gel, with } \\
\text { small grains }\end{array}$ & $\begin{array}{c}\text { Consistency gel- } \\
\text { like, with small } \\
\text { grains }\end{array}$ & $\begin{array}{c}\text { Consistency gel- } \\
\text { like, with small } \\
\text { grains }\end{array}$ \\
\hline The color & White & Pure white & Dull white & $\begin{array}{l}\text { White with a } \\
\text { beige shade }\end{array}$ \\
\hline The smell & Thin, light & Thin, pleasant & Pleasant lemon & Weak orange \\
\hline Taste & $\begin{array}{c}\text { Sweet to taste } \\
\text { with a pleasant } \\
\text { after feeling }\end{array}$ & $\begin{array}{c}\text { Sweet to taste } \\
\text { with a pleasant } \\
\text { after feeling }\end{array}$ & $\begin{array}{c}\text { Sweet to taste } \\
\text { with a pleasant } \\
\text { after feeling }\end{array}$ & $\begin{array}{c}\text { Sweet to taste } \\
\text { with a pleasant } \\
\text { after feeling }\end{array}$ \\
\hline
\end{tabular}

Samples of toothpaste №1, № 3 and № 4 with the content of CMC 1\% and carrageenan $2 \%$ and $3 \%$, were the best overall estimation for organoleptic quality.

We have chosen the following descriptors: consistency, color, smell, taste. Using the developed profiling table (Table 3), evaluated the quality of samples of the toothpaste with different content of carrageenan.

Table 3

Profiling descriptor toothpaste

\begin{tabular}{|c|c|}
\hline Valuation & Characteristics of organoleptic quality indices (descriptors) \\
\hline \multicolumn{2}{|r|}{ Consistence } \\
\hline 5 & Viscous, homogeneous pasty \\
\hline 4 & Paste, not homogeneous \\
\hline 3 & Not homogeneous, slightly liquid \\
\hline 2 & Inhomogeneous, liquid mass \\
\hline 1 & Inhomogeneous, camouflaged, liquid mass \\
\hline \multicolumn{2}{|r|}{ Color } \\
\hline 5 & Clean white \\
\hline 4 & White with a beige shade \\
\hline 3 & White with brown tint \\
\hline 2 & Beige color \\
\hline 1 & Light brown color \\
\hline \multicolumn{2}{|r|}{ Smell } \\
\hline 5 & Pleasant, according to the fillers used \\
\hline 4 & Characteristic, but less pronounced \\
\hline 3 & Slightly strong. \\
\hline 2 & Unpleasant, strong \\
\hline 1 & Strong, distorts the paste \\
\hline \multicolumn{2}{|r|}{ Taste } \\
\hline 5 & Sweet with a pleasant after taste \\
\hline 4 & Sweet \\
\hline 3 & Sweet with bitter after taste \\
\hline 2 & Sweet with sour after taste \\
\hline 1 & Bitter taste, unpleasant. \\
\hline
\end{tabular}


The descriptor-profile method sensory analysis is used for the study of cosmetic and food products. It is a method of scientific substantiation of the research and one of the methods of objective assessment of organoleptic parameters.

Using profiling table evaluated the quality of samples of toothpaste with different contents of carrageenan. Profilograms were constructed (Figure 2), the average estimate was calculated and the result was rounded to integer value for the purpose of visual perception of the results, profilographers were constructed, calculating the mean value of the estimation and rounding the result to the integer value.

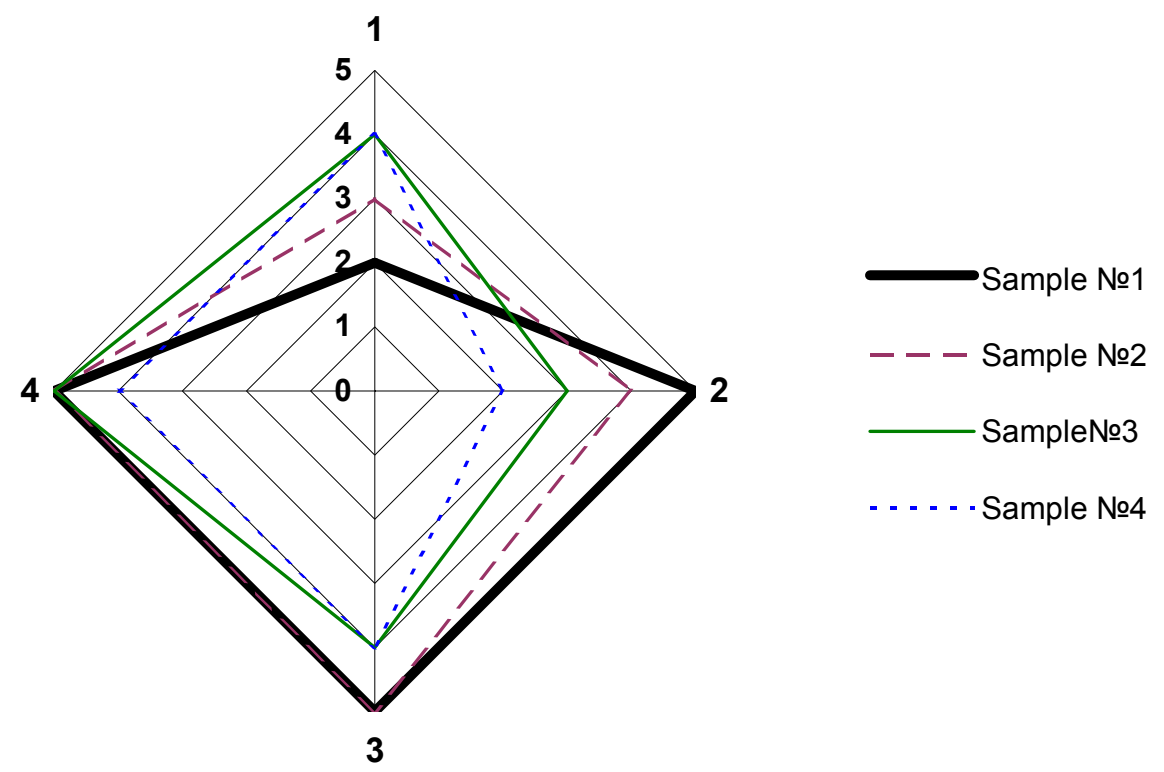

Figure 2. Prophylagram of evaluation of toothpaste samples.

The sides of the square are descriptors: 1 - consistency, 2 - color, 3 - smell, 4 - taste.

The best consistency has sample №3, the highest score by color was obtained samples of toothpaste №1 and №2. The smell and taste are satisfactory for all samples of toothpaste.

The rheological properties of the structured systems were studied. The potentiometer readings for each samples were studied at different (twelve) deformation rates and the steady stresses of the displacement $\mathrm{P}=$ const. The rheological parameters that characterized changing viscosity of the structured system in destruction of supramolecular structure as a result of the load were determined. The values: $\eta_{0}$ is the greatest viscosity of the system with practically no destroyed structure, $\eta_{\mathrm{m}}$ is the least viscosity of the system with a practically destroyed structure and their difference $\left(\eta_{0^{-}} \eta_{\mathrm{m}}\right)$, which is on the magnitude of the anomaly of viscosity and characterizes the strength of the system formed in the supramolecular system structures (Figure 2). 


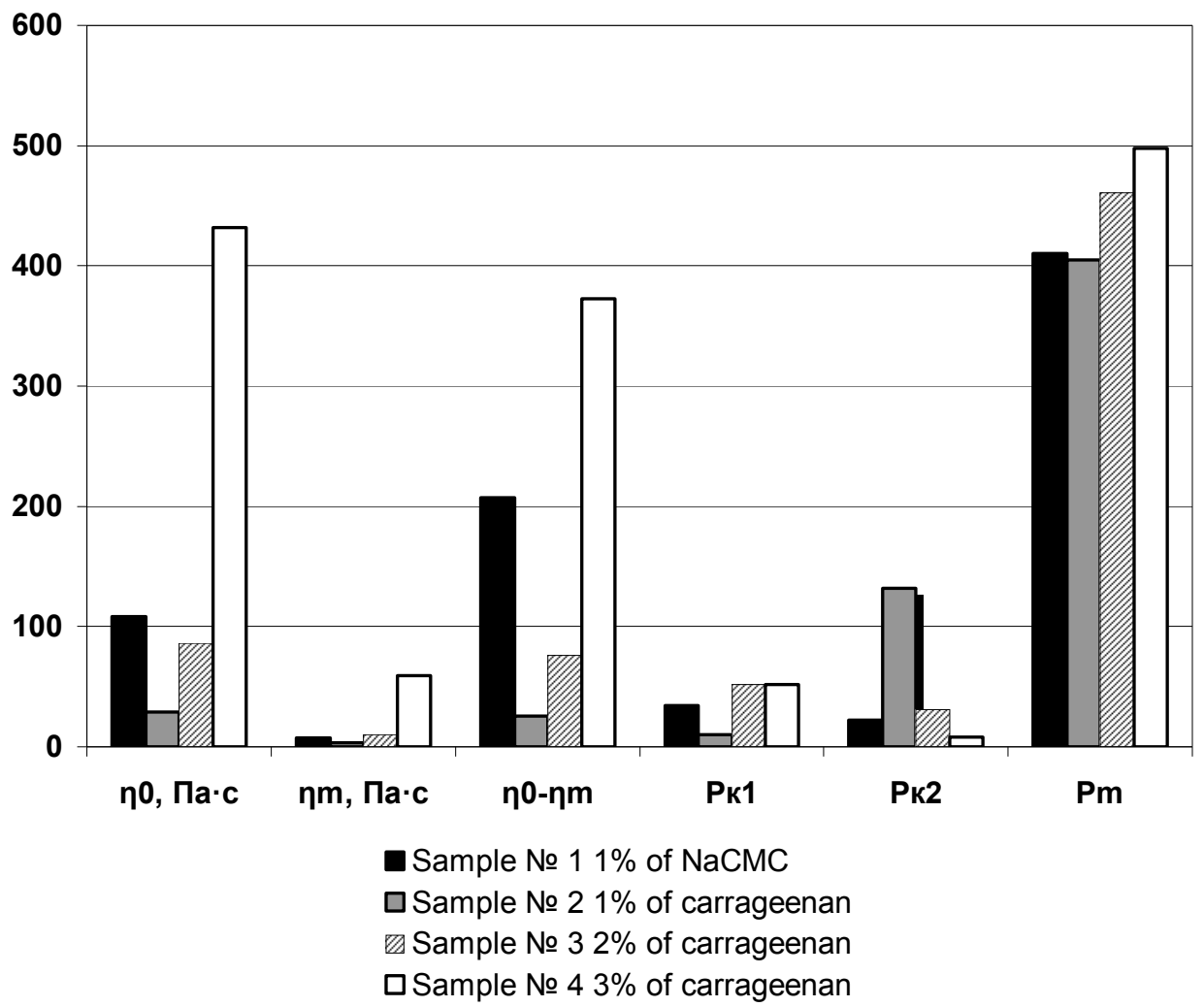

Figure 2. Viscosity and strength indicators for samples of paste with different contents of carrageenan

Some ratios of rheological parameters: $\mathrm{Pk}_{1} / \mathrm{Pk}_{2}$ characterizes the strength of structural bonds; $\mathrm{P}_{\mathrm{m}} / \mathrm{Pk}_{1}$ characterizes the range of stresses in which the structure is destroyed were calculated (Figure 3).

The parameters that characterize the change in the toothpaste viscosity in the destruction of supramolecular structure as a result of the load are determined. Calculated rheological parameters that characterize the strength of structural bonds and the range of stresses in which the destruction of the structure occurs.

The most expedient is the introduction of carrageenan in an amount of $2 \%$ to weight. The parameters of the highest viscosity of the system with practically no destroyed structure $\left(\eta_{\mathrm{m}}=76,16 \mathrm{~Pa} \cdot \mathrm{s}\right)$ and the least viscosity of the system with a practically destroyed structure $\left(\eta_{0}=86,37 \mathrm{~Pa} \bullet \mathrm{s}\right)$ are optimal. At the same time adding carrageenan create a gel-like consistency of toothpaste which meets the requirements of existing standards. The rheological parameters of this paste sample, which characterize the strength of structural bonds and the range of stresses in which structural destruction is taking place, are also satisfactory. 


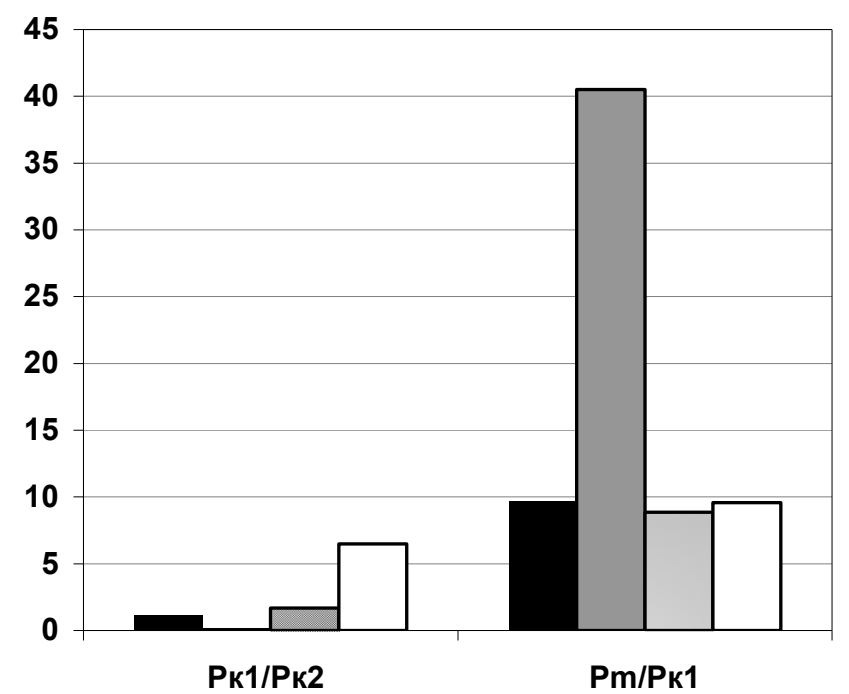

- Sample № $11 \%$ of NaCMC

$\square$ Sample № $21 \%$ of carrageenan

$\square$ Sample № $32 \%$ of carrageenan

$\square$ Sample № 4 3\% of carrageenan

Figure 3. Strength indicators for samples of paste with different contents of carrageenan

\section{Conclusion}

The studies confirm the expediency of the introduction of carrageenan in the amount of $2 \%$ to weight of the toothpaste. The viscosity $\left(\eta_{\mathrm{m}}=76,16 \mathrm{~Pa} \cdot \mathrm{s}, \eta_{0}=86,37 \mathrm{~Pa} \cdot \mathrm{s}\right)$ and the strength $\left(\mathrm{Pk}_{1} / \mathrm{Pk}_{2}=1,68\right)$ of the toothpaste obtained are optimal, and the best generalized organoleptic profile received a sample of toothpaste №3 with $2 \%$ carrageenan content. Since the toothpaste has a gel structure, the introduction of carrageenan optimizes the properties of the components of the toothpaste and promotes a rational impact on the physiological features of the oral cavity. This type of toothpaste is recommended to use for the general population.

\section{References}

1. Kirk I., (2013), Other chemical technology of cosmetics, JohnWiley \& Sons, Inc., pp. 822-824.

2. William R. Blakemore, (2016), Polysaccharide Ingredients: Carrageenan. Encyclopedia, Reference Module in Food Science, Elsevier. 
3. Vipul D. Prajapati, Pankaj M. Maheriya, Girish K. Jani, Himanshu K. Solanki (2014), RETRACTED: Carrageenan: A natural seaweed polysaccharide and its applications, Carbohydrate Polymers, 105, pp. 97-112.

4. Campo V.L., (2009), Carrageenans: Biological Properties, Chemical Modifications and Structural Analysis, Carbohydrate Polymers , 77, pp. 167-180.

5. Yermak I.M., Khotimchenko Y.S., (2003), Chemical properties, biological activities and applications of carrageenans from red algae, Biomaterials and bioprocessing, 9, pp. 207-255.

6. Chochkov R., ChonovV., Valova S., Karadzhov G., (2013), Rheological properties of fermented beverage from barley flour, Ukrainian Food Journal, 2(3), pp. 321-327.

7. Pabon P., Ternström S., Lamarche A., (2011), Fourier Descriptor Analysis and Unification of Voice Range Profile Contours: Method and Applications, Journal of Speech, Language, and Hearing Research, 54, pp. 755-776.

8. Pabon P., Ternström S., Lamarche A., (2011), Fourier Descriptor Analysis and Unification of Voice Range Profile Contours: Method and Applications, Journal of Speech, Language, and Hearing Research, 54, pp. 755-776. 